\title{
Body Composition Estimatives by Anthropometry, Bioelectrical Impedance and Deuterium Oxide Dilution in Obese Adolescents
}

\author{
Joyce M. Camarneiro",2*, José S. C. Júnior ${ }^{3}$, Luiz Antonio D. Ciampo ${ }^{3}$, Anderson M. Navarro ${ }^{4}$, \\ Gilmara A. Antonucci ${ }^{1}$, Jacqueline P. Monteiro ${ }^{5}$ \\ ${ }^{1}$ Faculty of Taquaritinga, União Nacional das Instituições Educacionais de São Paulo-UNIESP, Taquaritinga, Brazil; ${ }^{2}$ University \\ State Paulista-UNESP, Araraquara, Brazil; ${ }^{3}$ Department of Pediatrics, Faculty of Medicine of Ribeirão Preto, University of São \\ Paulo, Ribeirão Preto, Brazil; ${ }^{4}$ Department of Clinical Medics, Faculty of Medicine of Ribeirão Preto, University of São Paulo, \\ Ribeirão Preto, Brazil; ${ }^{5}$ Division of Nutrition and Metabolism, Department of Internal Medicine, Faculty of Medicine of Ribeirão \\ Preto, University of São Paulo, Ribeirão Preto, Brazil. \\ Email: ${ }^{*}$ joyce.camarneiro@gmail.com
}

Received March 15 $5^{\text {th }}, 2013$; revised April 15 $5^{\text {th }}, 2013$; accepted April 22 ${ }^{\text {nd }}, 2013$

Copyright (C) 2013 Joyce M. Camarneiro et al. This is an open access article distributed under the Creative Commons Attribution License, which permits unrestricted use, distribution, and reproduction in any medium, provided the original work is properly cited.

\begin{abstract}
To evaluate the relationship between measures of body composition in obese adolescents by the methods of bioelectrical impedance analysis, deuterium oxide dilution and anthropometric measures, proposing an equation. The variables were weight, height, BMI, triceps and subscapular skinfold thickness, waist and arm muscle circumference, lean body mass, fat mass and total body water by bioelectrical impedance and deuterium oxide dilution methods. The study included 40 obese adolescents, $45 \%$ male, age distribution was $2.42 \pm 1.19$ years and females $55 \%$, and the predominant age was $12.61 \pm 1.78$. Linear regression equations were developed, capable of predicting body composition from information supplied by the method of deuterium oxide dilution (gold standard), bioelectrical impedance and anthropometry. The variables gender, age, height, arm circumference, triceps and suprailiac skin fold thickness, resistance and reactance were used to estimate lean body mass, fat mass and total body water by the method of deuterium and significantly correlated with variables, resistance, reactance, sex and total body water (TBW) by bioimpedance method. Among the equations developed, five were suitable for this sample, therefore, it is suggested that more studies should be done to test the applicability of the equations in other samples so that we can validate the equations encountered in obese adolescents.
\end{abstract}

Keywords: Anthropometry; Bioelectrical Impedance Analysis; Deuterium Oxide Dilution; Obese Adolescents; Linear Regression Equation

\section{Introduction}

Overweight in childhood and adolescence has increased in our country due to changes in lifestyle, such as sedentary lifestyle and consumption of unhealthy foods [1]. Obesity is a chronic disease and interrelated directly or indirectly with other pathological conditions [2], and among its complications stands those related to metabolic syndrome $[3,4]$.

The prevalence of Brazilian adolescents who are overweight is $16.7 \%$, being more common in boys than in girls, and the South region has the highest rate in the country [5]. The changes in the cardiovascular system were investigated in young children in Curitiba and

${ }^{*}$ Corresponding author. found that the obese have higher rates of blood pressure, dyslipidemia and insulin resistance, compared to nonobese [6].

Obesity is the result of excess fatty tissue and, unfortunately, accurate measurement of total body fat requires sophisticated methods and they are often expensive and have limited applicability in clinical practice [7].

The World Health Organization (WHO) suggests using the Body Mass Index (BMI) to screen for overweight and obese adolescents because it is well correlated with body fat, easily accessible, benchmarks for comparison and also allow a continuous criteria that can be used for evaluation when adults. In fact, BMI is an index to measure overweight and not body fat, so the argument 
goes around its predictive ability in identifying youths with high body fat [8].

At the same time it has been evident in recent studies that the use of bioelectrical impedance analysis (BIA), an easy handling, cheap and practical to be applied in assessing the body composition of children, requires that the specific prediction formulas have to be different from those established for adults [4,5-10]. Equations were developed for the prediction of lean mass [4,7-10] and total body water $[5,6,10]$. BIA also could be an easy method, suitable for body composition assessment of obese children, but currently this is not possible due to lack of valid equations for the obese population.

In drawing up these equations, it is necessary to use methods such as deuterium dilution, considered a reference technique, safe and well established, a gold standard method for assessing body water compartments, even in childhood [11].

Therefore studies using reference methods for developing mathematical models to estimate body composition in obese adolescents are needed and scarce. Thereby this study aims to evaluate the relationship between measures of body composition in obese adolescents by anthropometric, bioelectrical impedance and deuterium oxide dilution, proposing an equation.

\section{Materials and Methods}

Adolescents were selected from the Community and Social Center of Vila Lobato HCFMRP/USP, Ribeirão Preto, assessed by anthropometry and body composition by bioelectrical impedance method and the method of deuterium oxide. The study was in accordance with the ethics Committee on Human Research (HCRP in 11227/2006). Informed written consent was obtained from parents and, when necessary, details on explanation about the study.

\subsection{Anthropometry}

Weight and height were evaluated according to the method of Heymsfield et al. (1994) [12] by a nutritionist, who was trained to take all necessary measures. The reference data used for the classification of nutritional status was BMI percentile for age greater than 97 according to WHO data, 2007 indicative of obesity [13].

The skinfolds were measured using Lange skinfold ${ }^{\circledR}$ Skinfold Caliper (Beta Technology Incorporated Cambridge, Maryland). Each measure was conducted three times being considered the average value of the three measurements. The triceps skinfold and subscapular skinfold were measured according to techniques described by Lohman, Roche and Martorell (1991) [14]. The classification of skinfold thickness was evaluated for the percentile values for age and sex as described by Fri- sancho (1990) [15]. The cutoff points for normal upper and lower percentiles were 5 and 85 , respectively.

\subsection{Bioelectrical Impedance Analysis}

The patient assumed the dorsal decubitus position, skin was cleaned with alcohol and were placed four surface electrodes. Two in the back of the hand, the distal electrode glued to the base of the middle finger and the proximal electrode glued to coincide with the styloid process. Two electrodes were placed on the instep, the distal electrode was pasted on the base of the middle finger and the proximal electrode between the medial and lateral malleolus [16]. The estimation of body composition was performed by applying an electric current of low intensity $(800 \mathrm{~mA})$ and fixed frequency of $50 \mathrm{kHz}$ [17] and then obtained the values of resistance and reactance. To determine the body composition an equation in the program of the QUADSCAN $\mathbf{4 0 0 0}$ unit was used and the equipment BODYSTAT ${ }^{\circledR} 1500$ especially suitable for ages 6 to 17 years, with the equation proposed by Houtkooper et al. (1992) [10] to estimate fat-free mass in children and adolescents.

$$
\begin{aligned}
\text { FFM }= & 1.31+\left(0.61 \times \text { height }(\mathrm{cm})^{2} / \text { resistance }\right) \\
& +0.25 \times \text { weight }(\mathrm{kg})
\end{aligned}
$$

\subsection{Deuterium Dilution Method}

Immediately after the anthropometric measures and BIA, saliva collection started and deuterium oxide was offered, making sure that the examinations were made at the same time and under the same conditions, therefore, the hydration status was unchanged in all measurements used in this study [18].

Three samples of saliva were collected: a baseline sample, before intake of the dose, the second sample was taken two hours after ingestion of the dose and the third and final sample, three hours after ingesting the dose. The saliva collection was done through the salivation of the patient in a plastic cup until it reaches the amount of two milliliters. The samples were immediately transported to cryovials with PP screw cap, through a disposable syringe and wrapped with parafilm, thus allowing the best seal for each sample, avoiding possible evaporation losses during handling of vials, and avoiding contamination crossed between samples during the storage period [19].

Before receiving the isotope, each juvenile was weighed and the doses were calculated using the ratio of one gram of deuterium to one kilogram of body weight $[17,19]$. To avoid losses after the patient had swallowed the entire contents of the glass, he or she was asked to rinse to ingest residues of the dose which by chance was in the mouth. 
After ingestion of the doses, the saliva was stored in a freezer with temperature $-20^{\circ} \mathrm{C}[1,20]$, analyzed for enrichment of deuterium $(2 \mathrm{H})$, using a Mass Spectrometer calibrated against Vienna Standard Mean Ocean Water (VSMOW) and 302A and 302B of the International Atomic Energy Agency (IAEA). The total body water was calculated at $\mathrm{T}_{0}$ (baseline) and $\mathrm{T}_{\text {equ }}(3 \mathrm{~h}$ ), using a correction factor of $4 \%$ considering the exchange ${ }^{2} \mathrm{H}_{2} \mathrm{O}$ with the labile $\mathrm{H}$ of proteins and other body constituents.

\subsection{Statistical Analysis}

A descriptive analysis of data was first conducted. The t-test $(\mathrm{p}<0.05)$ of average comparison was performed between measures of body composition (BIA), deuterium, waist circumference, skinfold thickness, weight, height, age and BMI.

We used the concordance coefficient, introduced by St. Laurent (1998) [21], for continuous variables since has been considered adequate to evaluate the concordance. Using the software SAS 9.1, the coefficients and their 95\% confidence intervals were calculated, via bootstrap method. To formulate the equation of estimating body composition prepared from a gold standard (deuterium oxide dilution) using direct measurements such as circumference, skinfold thickness measurements and BIA statistical method of multiple linear regressions was used
(GLM SAS 9.1 software) [22] This method consists of adjusting a function to the set of points defined by quantitative variables so that the distance between the function and the points are minimal.

The first step of this method is the study of covariance and correlation to identify whether there is a relationship between variables. The relationship between two variables will be represented by a function $(y=a+b x)$.

The second step is to obtain an equation that represents the function of causality between two variables, performing a curve fit to existing data.Multiple linear regression includes the same process as a function of more than two dependent variables [23].

\section{Results}

The study included 40 obese adolescents, $45 \%$ male, age distribution was $2.42 \pm 1.19$ years and females $55 \%$, and the predominant age was $12.61 \pm 1.78$ and these were submitted to anthropometric evaluation and body composition analysis by bioelectrical impedance method and by dilution of deuterium oxide.

Regarding the distribution of adolescents according to sexual maturation, we observed that both males and females were in stage three of Tanner [24].

Tables 1-3 have the descriptions of the variables by the anthropometric method, bioelectrical impedance and deuterium oxide dilution according to sex and variables.

Table 1. Anthropometric characterization of the study group by gender. Ribeirão Preto-SP, 2011.

\begin{tabular}{|c|c|c|c|c|c|c|c|}
\hline Gender & $\mathbf{N}$ & Variable & Minimum & 1st Quartile & Median & 3rd Quartile & Maximum \\
\hline \multirow[t]{8}{*}{$\mathbf{F}$} & 24 & BMI $\left(\mathrm{Kg} / \mathrm{m}^{2}\right)$ & 29.5 & 30.0 & 30.4 & 30.4 & 30.5 \\
\hline & & Age (years) & 11.00 & 11.50 & 13.00 & 13.00 & 14.00 \\
\hline & & Height $(\mathrm{cm})$ & 142.00 & 153.00 & 154.00 & 156.50 & 171.00 \\
\hline & & Weight (Kg) & 60.30 & 65.10 & 70.30 & 76.05 & 83.10 \\
\hline & & Triceps Skinfold (mm) & 14.50 & 15.00 & 17.00 & 18.50 & 27.00 \\
\hline & & Subscapular Skinfold (mm) & 16.00 & 20.00 & 28.75 & 34.00 & 41.00 \\
\hline & & $\mathrm{WC}(\mathrm{cm})$ & 71.30 & 78.85 & 81.25 & 87.75 & 96.50 \\
\hline & & Arm Muscle Circumference (cm) & 8.71 & 10.07 & 10.31 & 10.49 & 11.52 \\
\hline \multirow[t]{8}{*}{$\mathbf{M}$} & 16 & BMI $\left(\mathrm{Kg} / \mathrm{m}^{2}\right)$ & 29.6 & 30.1 & 30.7 & 30.8 & 31.1 \\
\hline & & Age (years) & 10.00 & 12.00 & 13.00 & 14.00 & 15.00 \\
\hline & & Height $(\mathrm{cm})$ & 141.00 & 152.50 & 155.50 & 158.00 & 167.00 \\
\hline & & Weight (Kg) & 60.10 & 67.25 & 70.10 & 75.85 & 81.20 \\
\hline & & Triceps Skinfold (mm) & 14.00 & 16.00 & 18.25 & 21.00 & 26.00 \\
\hline & & Subscapular Skinfold (mm) & 19.00 & 25.00 & 27.00 & 29.00 & 34.00 \\
\hline & & $\mathrm{WC}(\mathrm{cm})$ & 69.10 & 77.75 & 78.85 & 84.20 & 97.10 \\
\hline & & Arm Muscle Circumference (cm) & 0.63 & 9.40 & 10.25 & 10.68 & 11.21 \\
\hline
\end{tabular}

BMI—body mass index; WC—-waist circumference; $\mathrm{AMC}=$ arm muscle circumference. 
Table 2. Characterization of the bioelectrical impedance method in the study group by gender. Ribeirão Preto-SP, 2011.

\begin{tabular}{|c|c|c|c|c|c|c|c|}
\hline Gender & $\mathbf{N}$ & Variable & Minimum & 1st Quartile & Median & 3rd Quartile & Maximum \\
\hline \multirow[t]{5}{*}{$\mathbf{F}$} & 24 & LMBIA (Kg) & 22.40 & 33.40 & 38.85 & 45.45 & 52.10 \\
\hline & & FMBIA (Kg) & 26.80 & 28.90 & 31.50 & 35.65 & 37.90 \\
\hline & & TBWBIA (\%) & 68.30 & 71.35 & 72.65 & 74.40 & 76.50 \\
\hline & & Resistence & 269.37 & 284.21 & 297.62 & 335.54 & 391.34 \\
\hline & & Reactance & 30.59 & 32.28 & 33.80 & 38.11 & 44.44 \\
\hline \multirow[t]{5}{*}{ M } & 16 & LMBIA (Kg) & 19.10 & 31.35 & 37.55 & 43.30 & 52.40 \\
\hline & & FMBIA (Kg) & 25.80 & 30.05 & 33.90 & 37.20 & 41.00 \\
\hline & & TBWBIA (\%) & 63.30 & 69.25 & 72.15 & 72.90 & 75.60 \\
\hline & & Resistence & 269.84 & 284.21 & 289.62 & 323.29 & 350.37 \\
\hline & & Reactance & 30.64 & 32.28 & 32.89 & 36.72 & 39.79 \\
\hline
\end{tabular}

LMBIA $\%$ = lean body mass by the method by bioimpedance; FMBIA $\%$ = fat mass by the method by bioimpedance; TBWBIA = body water by bioimpedance method.

Table 3. Characterization of the method of deuterium oxide dilution in the study group by gender. Ribeirão Preto-SP, 2011.

\begin{tabular}{ccccccccc}
\hline Gender & N & Variable & Minimum & 1st Quartile & Median & 3rd Quartile & Maximum \\
\hline $\mathbf{F}$ & $\mathbf{2 4}$ & LMDEU (Kg) & 35.30 & 42.60 & 47.30 & 49.50 & 59.80 \\
& & FMDEU (Kg) & 16.60 & 20.10 & 21.40 & 26.05 & 40.00 \\
$\mathbf{M}$ & $\mathbf{1 6}$ & TBWDEU (\%) & 54.90 & 61.20 & 65.90 & 69.95 & 75.90 \\
& & LMDEU (Kg) & 40.70 & 46.55 & 49.45 & 55.65 & 64.80 \\
& & FMDEU (Kg) & 13.10 & 18.20 & 18.95 & 22.75 & 27.80 \\
\hline
\end{tabular}

LMDEU $\%$ = lean body mass by the method of deuterium; FMDEU\% $=$ fat mass by the method of deuterium; TBWDEU $\%=$ body water by the method of deuterium.

Figure 1 shows the graphs of points for the anthropometric measurements (skinfold thickness), bioelectriccal impedance and deuterium, and the concordance coefficients of St. Laurent - CCSL (ranging between 0 and 1), their respective ranges $95 \%$ confidence, and the coefficient of determination $\left(\mathrm{R}^{2}\right)$. The closer to 1 , a greater concordance between the methods. According to the findings, we need to verify, using the linear regression equation, the possibility of predicting body composition measurements supplied by the method of dilution of deuterium oxide (gold standard), from measurements of BIA and anthropometry using the variables sex, age, height, arm, and triceps and suprailiac skinfold thickness, resistance and reactance to estimate lean body mass, fat mass and total body water, as shown in Table 4.

From these results, five equations were considered favorable to estimate lean body mass, fat mass and total body water by the method of deuterium, as shown in Table 5 .

\section{Discussion}

Obesity is a complex and multifactorial disease that involves the interaction of metabolic, physiological, behavioral and social variables. Among environmental factors, the highlights are for the poor dietary habits and sedentary lifestyles $[25,26]$.

In this study, in relation to pubertal stage, $57.5 \%$ of female adolescents and $40.0 \%$ of male patients met the three Tanner stage, characterized by the onset of pubertal development and none was in stage five, indicating that most have not completed the growth spurt.

According to Siervogel et al. (2003) [22], changes in body composition occur during puberty in both sexes. In this period there is rapid increase in body fat, although this increase is slower in males, being that overcome by lean body mass. These changes are justified because of increased energy requirements in adolescents associated with changes in body composition.

In relation to waist circumference, the overall average 


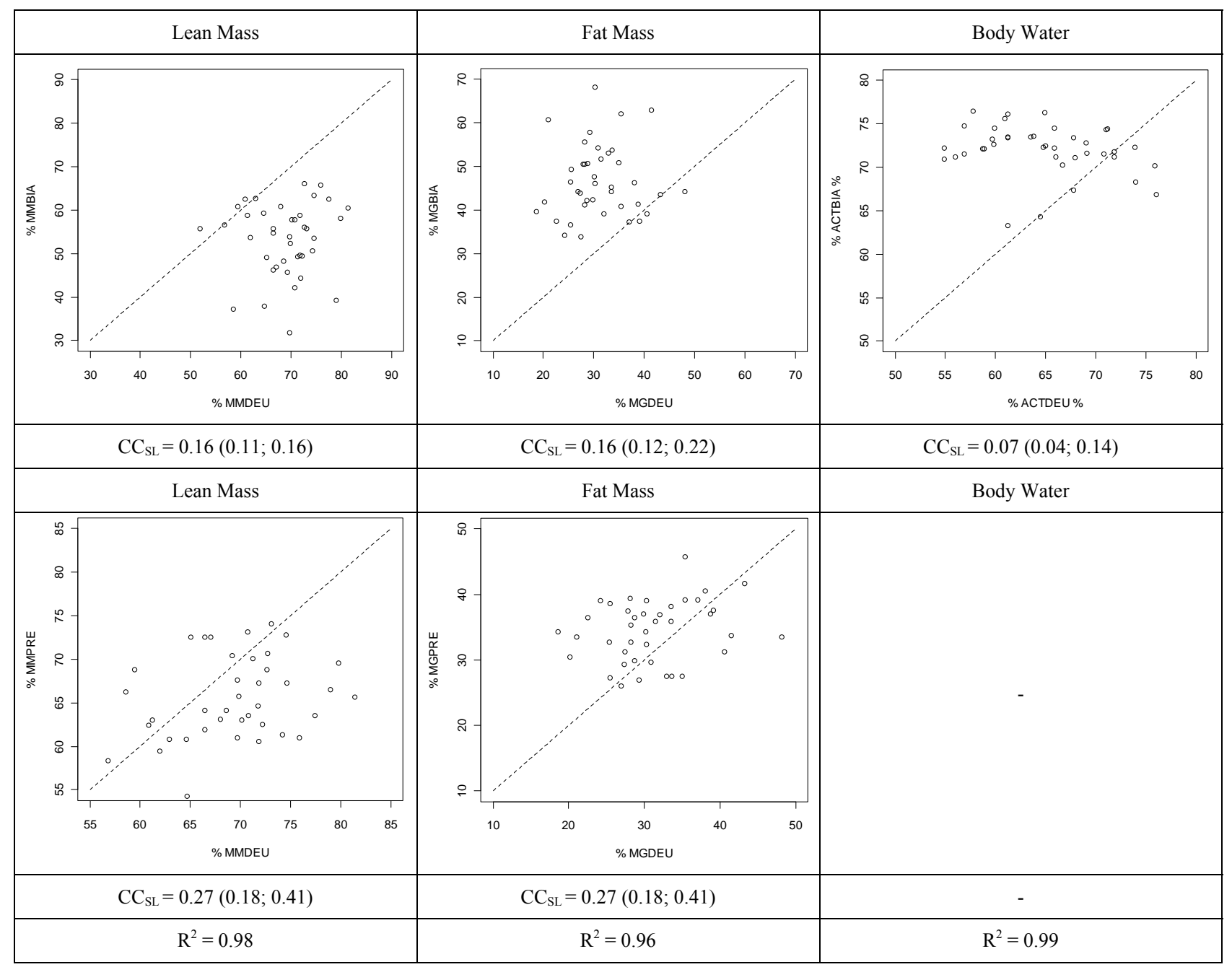

Figure 1. Relation of coefficient of correlation between the Lean Mass DEU (kg) with Lean Mass BIA (kg), Fat Mass DEU (Kg) with Fat Mass BIA (kg) also the TBWDEU (\%) and TBWBIA (\%) of adolescents in the Community and Social Center of Vila Lobato HCFMRP/HCFMRP USP/USP, from July 2008 to May 2009. Ribeirão Preto, 2010.

of $81.25 \mathrm{~cm}$ was found and there was no statistically significant difference between gender $\mathrm{p}=0.86$ ) [27].

Sudi et al. (2001) [28] evaluated the waist circumference in obese adolescents, and the average found in relation to waist circumference was $89.5 \mathrm{~cm}$ for males and $87.4 \mathrm{~cm}$ for females, being above the 95 th percentile. Lazzer et al. (2008) [29], studying measures of waist circumference in obese adolescents, found average values equal to $111 \mathrm{~cm}$ for both girls and boys. The authors also found no significant difference between the sexes.

Lazzer et al. (2008) [29] studied 58 obese adolescents aged between 10 and 17 years (27 males and 31 females) and found BMI values similar to ours. The averages for females and males were also equal to $36.2 \mathrm{~kg} / \mathrm{m}^{2}$ and $32.2 \mathrm{~kg} / \mathrm{m}^{2}$, respectively, without statistical differences.

Considering that the individuals studied are in the process of sexual maturation, and that this fact can in- fluence the interpretation of BMI as an indicator of risk of overweight and obesity, several authors claim that, in boys, BMI increases while the fat mass decreases in the final stages of maturation, indicating that male adolescents increased BMI because of lean muscle mass. In girls, there is an increase in BMI rise as the stages of maturation, but also increases the percentage of body fat, indicating that increased BMI is due to the increase in fat stores [2,30]. This fact could be justifying the values found in this study, in other words, a larger amount of fat found in females when compared to males.

By assessing the body composition by BIA in relation to variables, lean body mass, fat mass and percentage of total body water, there was no statistically significant difference between the sexes in relation to lean body mass $(p=0.95)$, mass body fat $(p=0.96)$ and total body water $(p=0.36)$. 
Table 4. Equations for estimating body composition by the method of dilution of deuterium oxide using measures of anthropometry and bioimpedance. Ribeirão Preto-SP, 2011.

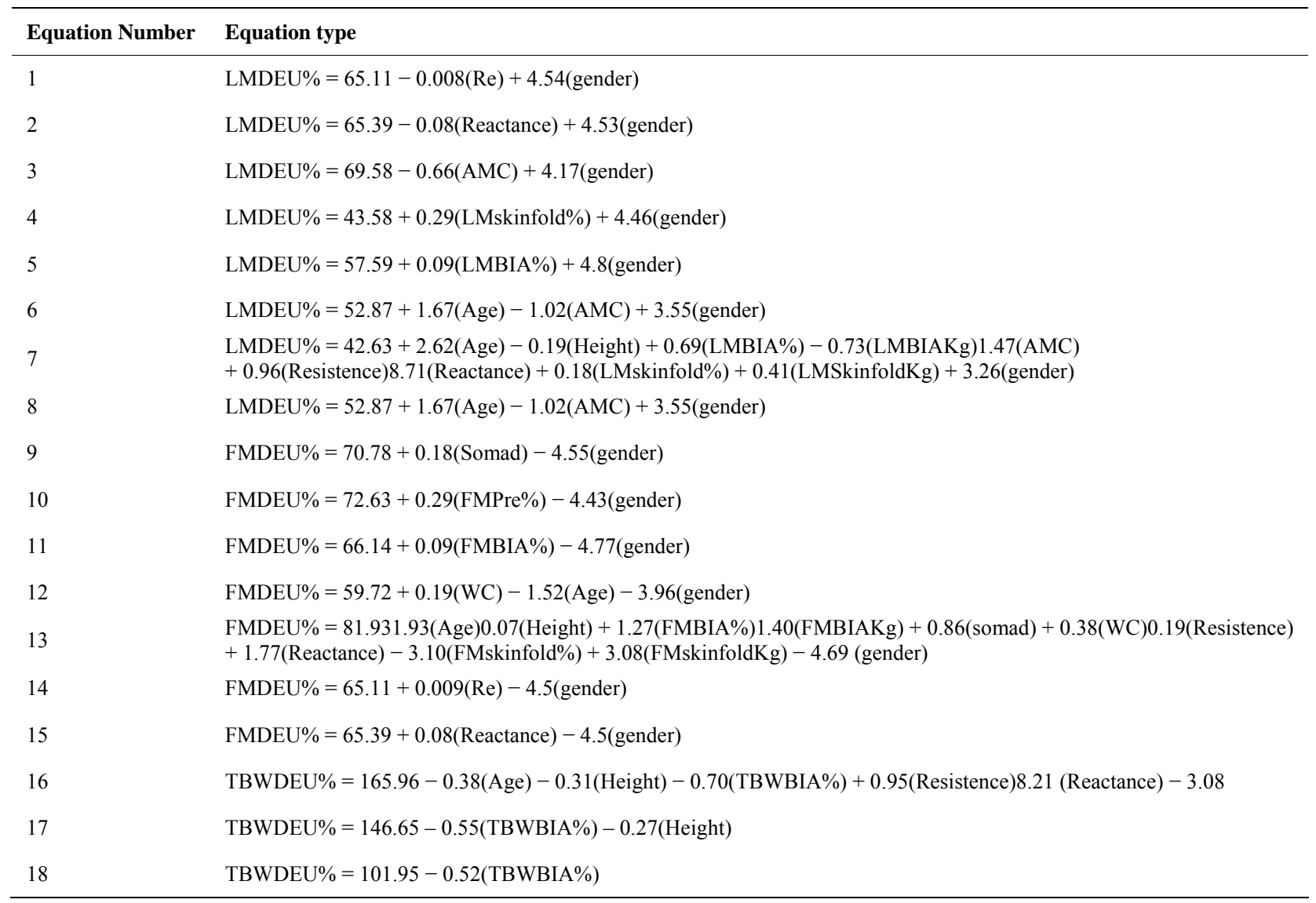

LMDEU $\%$ = lean body mass by the method of deuterium; FMDEU\% = fat mass by the method of deuterium; Re $=$ resistance $(\Omega)$; TBWDEU\% $=$ body water by the method of deuterium; TBWBIA = body water by bioimpedance method; LMskinfold $\%$ = lean mass by skinfolds; Somad = sum of skinfold thickness; FMskinfold $\%=$ fat mass by skinfolds; $\mathrm{WC}=$ waist circumference; $\mathrm{AMC}=$ arm muscle circumference.

Table 5. Equations for estimating body composition by the method of dilution of deuterium oxide measurements using bioelectrical impedance. Ribeirão Preto-SP, 2011.

\begin{tabular}{ll}
\hline Equation Number & Equation \\
\hline 1 & LMDEU $\%=65.11-0.008($ Re $)+4.54$ (gender) \\
2 & LMDEU\% $=65.39-0.08$ (Reactance) +4.53 (gender) \\
3 & FMDEU $\%=65.11+0.009($ Re $)-4.5$ (gender) \\
4 & FMDEU $\%=65.39+0.08($ Reactance $)-4.5$ (gender) \\
5 & TBWDEU\% $=101.95-0.52$ (TBWBIA $\%)$ \\
\hline
\end{tabular}

$\mathrm{LMDEU}=\%$ lean mass by the method of deuterium; FMDEU $\%=$ fat mass by the method of deuterium; Re $=$ resistance $(\Omega)$; TBWDEU $\%=$ body water by the method of deuterium; TBWBIA = body water by bioimpedance method.

Eisenkölbl, Kartasurya e Widhalm (2001) [31], studying children and adolescents with average BMI equal to $32.3 \mathrm{~kg} / \mathrm{m}^{2}$ for boys and $30.14 \mathrm{~kg} / \mathrm{m}^{2}$ for girls found fat mass assessed by BIA equal to $32.21 \%$ for males and $38.48 \%$ for females, higher values to those found in our results.

The BIA is a noninvasive safe method and it is por- table, and is widely used to estimate body composition $[31,32]$. It is well established the importance in relation to the definition of body composition to assess and monitor obesity. However, several factors limit its use in obese adolescents [33]. The prediction equations developed for normal individuals, generally overestimates the lean body mass in extremely obese adults [31]. 
In relation to body composition assessed by dilution of deuterium oxide, considering variables, lean body mass, fat mass and total body water, there was no statistically significant difference between the sexes.

The average body fat found in our study through the method of dilution of deuterium oxide was $22.75 \%$ for males and $26.05 \%$ for females. Above referenced Fomon et al. (1982) [34] for children and healthy adolescents 10 years old with $13.7 \%$ body fat for boys and $19.4 \%$ body fat for girls.

The deuterium dilution method has brought in recent years, valuable information in relation to body composition, contributing to the systematic understanding of nutritional conditions in different scenarios, particularly in the pediatrics [35].

The results obtained by the BIA, when compared with data from the method of dilution of deuterium oxide, showed a weak correlation for the variables lean body mass and total body water and a strong correlation to body fat mass. This result indicates that we can use bioelectrical impedance analysis with the formula Houtkooper et al. (1992) [10] to assess body fat mass of obese adolescents in this study, however, despite good correlation, after the agreement analysis (Figure 1), we find that this concordance was not close to 1 and thus, even the formula Houtkooper et al. (1992) [10], widely used in pediatrics to assess body composition determined by BIA, was not efficient to predict the real value of decomposing body in adolescents obese.

Kushner and Schoeller (1986) [36], compared the TBW assessed by BIA with TBW measured by dilution of deuterium oxide in 58 adult subjects. The authors concluded that the BIA has proved an accurate method for predicting body water obtained by dilution of deuterium oxide by means of multiple regression equations.

There are studies in literature that were designed to predict total body water determined by deuterium diluted in the eutrophic children and adolescents [6] and obese ones $[3,37]$ using measurements provided by the BIA, through equations. These studies used values of resistance indices (height ${ }^{2} /$ resistance), age, weight and body surface/body impedance adjustment of the regression model. This study differs from these studies due to the adjustment variables included in the regression model, there is no work in the literature that used the same variables.

Table 5 presents the 17 equations developed, but the variables, sex, age, height, arm, triceps and suprailiac skinfold thickness, resistance and reactance, were used to estimate lean body mass, fat mass and total body water by method of deuterium and significantly correlated with the variable resistance, reactance, sex and total body water by bioimpedance method. And from these equations, only five formulas have been suggested, using the method of electric bioimpedance to assess body composition of obese adolescents.

Finally, several studies have shown that anthropometric measures such as weight, height and skinfold thickness are not applicable to assess body composition. We noticed the need of a viable method for assessing body composition in clinical practice for better monitoring the obese adolescents. The BIA is a simple method and its results are delivered quickly, but you need to adjust specific formulas for assessing children and adolescents, especially when it comes to obesity. Therefore the formulas suggested in this study could assist health professsionals in the assessment of body composition in obese adolescents, not limited to body mass index, a criterion that does not measure body fat and lean mass. But it is not appropriate to extrapolate these equations outside the context of the data. In other words, while the linear regression models were adjusted well, it is necessary to validate the applicability of these formulas and possibly include other important variables in the model, pubertal stage for both will require a multiple regression analysis and also a bigger sample size.

\section{Conclusions}

This work was possible the construction of the linear regression equations, through measures of body composition provided by the method to dilution of deuterium oxide (gold standard) and by BIA, considering that the equation will be used only in obese adolescents belonging to the region of Social Center of Vila Lobato-RP and which are within the minimum and maximum values for lean body mass, fat mass and total body water of this population.

The equations developed were suitable for this sample, therefore, suggests that other studies test the applicability of the equations in other samples so that we can validate the equations encountered in obese adolescents.

\section{REFERENCES}

[1] E. Albernaz, C. G. Victora, H. Haisma, A. Wright and W. A. Coward, "Lactation Couseling Increases Breast-Feeding Duration but Not Breast Milk Intake as Measured by Isotopic Methods," Journal of Nutrition, Vol. 133, No. 1, 2003, pp. 205-209.

[2] K. B. F. Barbosa, S. C. C. Franceschini and S. E. Priore, "Influência dos Estágios de Maturação Sexual No Estado Nutricional, Antropometria e Composição Corporal de Adolescentes," Revista Brasileira de Saúde Materno-Infantil, Vol. 6, No. 4, 2006, pp. 375-382. http://dx.doi.org/10.1590/S1519-38292006000400003

[3] N. Battistini, P. Brambilla, F. Virgili, P. Simone, G. Bedogni, P. Morini and G. Chiumello, "The Prediction of 
Total Body Water from Body Impedance in Young Obese Subjects," International Journal of Obesity, Vol. 16, No. 3, 1992, pp. 207-212.

[4] L. Cordain, R. E. Whicker and J. E. Johnson, "Body Composition Determination in Children Using Bioelectrical Impedance," Growth, Development, and Aging: GDA, Vol. 52, No. 1, 1988, pp. 37-40.

[5] L. C. Danford, D. A. Schoeller and R. F. Kushner, "Comparision of Two Bioelectrical Impedance Analysis Models for Total Body Water Measurement in Children," Annals of Human Biology, Vol. 19, No. 6, 1992, pp. 603-607. http://dx.doi.org/10.1080/03014469200002422

[6] P. S. W. Davies, M. A. Preece, C. J. Hicks and D. Halliday, "The Prediction of Total Body Water Using Bioelectrical Impedance in Children and Adolescents," Annals of Human Biology, Vol. 15, No. 3, 1988, pp. 237-240. http://dx.doi.org/10.1080/03014468800009681

[7] P. Deurenberg, K. Van Der Kooy, R. Leenen, J. A. Wetstrate and J. C. Seidell, "Sex and Age Specific Prediction Formulas for Estimating Body Composition from Bioelectrical Impedance: A Cross-Validation Study," International Journal of Obesity, Vol. 15, No. 1, 1991, pp. 1725.

[8] A. C. R. Vieira, M. M. Alvarez, V. M. R. Martins, R. Sichieri and G. V. Veiga, "Desempenho de Pontos de Corte de Índice de Massa Corporal de Diferentes Referências na Predição de Gordura Corporal em Adolescentes," Caderno de Saúde Pública, Vol. 22, No. 8, 2006, pp. 1681-1690. http://dx.doi.org/10.1590/S0102-311X2006000800016

[9] P. Deurenberg, K. Van Der Kooy, A. Paling and P. Withagen, "Assessment of Body Composition in 8-11 Year Old Children by Bioelectrical Impedance," European Journal of Clinical Nutrition, Vol. 43, No. 9, 1989, pp. 623-629.

[10] L. B. Houtkooper, S. B. Going, T. G. Lohman, A. F. Roche and M. Van Loan, "Bioelectrical Impedance Estimation of Fat-Free Body Mass in Children and Youth: A CrossValitation Study," Journal of Applied Physiology, Vol. 72, No. 1, 1992, pp. 366-373.

[11] M. Elia, P. Betts, D. M. Jackson and J. Mulligan, "Fetal Programming of Body Dimensions and Percentage Body Fat Measured in Prepuberal Children with a 4-Component Model of Body Composition, Dual Energy X-Ray Absortiometry, Deuterium Dilution, Densitometry and Skinfold Thickness," The American Journal of Clinical Nutrition, Vol. 86, 2001, pp. 618-624.

[12] S. B. Heymsfield, A. Tighe and Z. M. Wang, "Nutritional Assessment by Anthropometric and Biochemical Methods," In: M. E. Shils, J. A. Olson and M. Shine, Eds., Modern Nutrition in Health and Disease, Lea Febiger, Malvern, 1994, pp. 812-841.

[13] World Health Organization, "Grow Reference 5-19 Years. Body Mass Index for Age (5-19 Years), Percentiles Girls and Boys," 2007.

http://www.who.int/growthref/who2007_bmi_for\%20age/ en/index.html

[14] T. G. Lohman, A. F. Roche and R. Martorell, "Antro- pometric Standarization Reference Manual," Abridged Editions, Champaign Human Kinetics Books, 1991.

[15] A. R. Frisancho, "Antropometric Standads for the Assessment of Growth and Nutrition Status," The University of Michigan Press, Ann Arbor, 1990.

[16] H. C. Lukaski, "Methods for the Assessment of Human Body Composition: Traditional and New," The American Journal of Clinical Nutrition, Vol. 46, No. 4, 1987, pp. 537-556.

[17] F. Schaefer, M. Georgi, A. Zieger and K. Schärer, "Usefulness of Bioelectrical Impedance and Skinfold Measurements in Predicting Fat-Free Mass Derived from Total Body Potassium in Children," Pediatric Research, Vol. 35, No. 5, 1994, pp. 617-624. http://dx.doi.org/10.1203/00006450-199405000-00016

[18] A. Dioum, A. Gartner, A. S. Cissé, F. Delpeuch, B. Maire, S. Wade and Y. Schutz, "Validity of Impedance-Based Equations for the Prediction of Total Body Water as Measured by Deuterium Dilution in African Women," The American Journal of Clinical Nutrition, Vol. 81, No. 3, 2005, pp. 597-604.

[19] L. B. Houtkooper, T. G. Lohman, S. B. Going and W. H. Howell, "Why Bioelectrical Impedance Analysis Should Be Used for Estimating Adiposity," The American Journal of Clinical Nutrition, Vol. 64, No. S3, 1986, pp. S436-S448.

[20] F. R. Vio, C. B. Infante, W. C. Lara and F. MardonesSantander, "Validation of the Deuterium Dilution Technique for the Measurement of Fluid Intake in Infants," Human Nutrition Clinical Nutrition, Vol. 40, No. 5, 1986, pp. 327-332.

[21] R. T. St. Laurent, "Evaluation Agreement with a Gold Standard in Methods Comparisons," Biometrics, Vol. 54, No. 2, 1998, pp. 537-545. http://dx.doi.org/10.2307/3109761

[22] R. M. Siervogel, E. W. Demerath, C. Schubert, K. E. Remsberg, W. C. Chumlea, S. Sun, S. A. Czerwinski and B. Towne, "Puberty and Body Composition," Hormone Research, Vol. 60, No. S1, 2003, pp. 36-45. http://dx.doi.org/10.1159/000071224

[23] J. H. Zar, "Biostatiscal Analysis," Prentice Hall, New Jersey, 1996.

[24] J. M. Tanner, "Growth al Adolescence," 2nd Edition, Blackwell Scientifie Publications, Oxford, 1962.

[25] A. Dâmaso, "Obesidade," Guanabara Koogan, Rio de Janeiro, 2003.

[26] D. P. Guedes and J. E. R. P. Guedes, "Manual Prático Para Avaliação em Educação Física," Manole, Barueri, 2006.

[27] H. D. Mccarthy, K. V. Jarrett and H. F. Crawley, "The Development of Waist Circumference Percentiles in British Children Aged 5.0-16.9 y," European Journal of Clinical Nutrition, Vol. 55, No. 10, 2001, pp. 902-907. http://dx.doi.org/10.1038/sj.ejcn.1601240

[28] K. M. Sudi, S. Gallistl, M. Tröbinger, D. Payerl, R. Aigner and M. H. Borkenstein, "The Effects of Changes in Body Mass and Subcutaneous Fat on the Improvement in 
Metabolic Risk Factores in Obese Children after ShortTerm Weight Loss," Metabolism: Clinical and Experimental, Vol. 50, No. 11, 2001, pp. 1323-1329. http://dx.doi.org/10.1053/meta.2001.27230

[29] S. Lazzer, G. Bedogni, F. Agosti, A. De Col, D. Mornati and A. Sartorio, "Comparison of Dual-Energy X-Ray Absorptiometry, Air Displacement Plethysmography and Bioelectrical Impedance Analysis for the Assessment of Body Composition in Severely Obese Caucasian Children and Adolescents," The British Journal of Nutrition, Vol. 100, No. 4, 2008, pp. 1-7. http://dx.doi.org/10.1017/S0007114508922558

[30] R. M. Malina and P. T. Katzmarzyk, "Validity of the Body Mass Índex as an Indicator of the Risk and Presence of Overweight in Adolescent," American Journal of Clinical Nutrition, Vol. 70, No. S1, 1999, pp. 131-136.

[31] J. Eisenkölbl, M. Kartasurya and K. Widhalm, "Underestimation of Percentage Fat Mass Measured by Bioelectrical Impendance Analysis Compared to Dual Energy XRay Absorptiometry Method in Obese Children," European Journal of Clinical Nutrition, Vol. 55, No. 6, 2001, pp. 423-429. http://dx.doi.org/10.1038/sj.ejen.1601184

[32] E. Ferrioli, B. M. Cruz and K. Pfrimer, "Uso de Isótopos Leves em Ciências Nutricionais," Ciências Nutricionais: Aprendendo a Aprender, 2nd Edition, Sarvier, São Paulo,
2008, pp. 443-465.

[33] J. C. Well, N. J. Fuller, O. Dewit, M. S. Fewtrell, M. Elia and T. J. Cole, "Four-Component Model of Body Composition in Children: Densty and Hydration of Fat-Free Mass ad Comparison with Simpler Model," The American Journal of Clinical Nutrition, Vol. 69, No. 5, 1999, pp. 904-912.

[34] S. J. Fomon, F. Haschke, E. E. Ziegler and S. E. Nelson, "Body Composition of Reference Children from Birth to Age 10 Years," The American Journal of Clinical Nutrition, Vol. 35, No. 5, 1982, pp. 1169-1175.

[35] L. Â. M. Traver, "Determinação do Tempo de Equilíbrio (Patamar) do Óxido de Deutério na Saliva de RecémNascidos a Termo Saudáveis," Universidade de São Paulo, Ribeirão Preto, 2007.

[36] R. F. Kushner and D. A. Schoeller, "Estimation of Total Body Water by Bioelectrical Impedance Analysis," The American Journal of Clinical Nutrition, Vol. 44, No. 3 , 1986, pp. 417-424.

[37] M. Wabitsch, U. Braun, E. Heinze, M. Muche, H. Mayer, W. Teller and C. Fusch, "Body Composition in 5-18-yOld Obese Children and Adolescents before and after Weight Reduction as Assessed by Deuterium Diluition and Bioelectrical Impedance," The American Journal of Clinical Nutrition, Vol. 64, No. 1, 1996, pp. 1-6. 